\title{
IMPLEMENTASI ALGORITMA ELGAMAL DAN KODE HILL UNTUK KEAMANAN DATABASE
}

\author{
Nasrudin ${ }^{1}$, Agung Pratama ${ }^{2}$, \\ Ega Pratama ${ }^{3}$, Ella Tri \\ Wulandari $^{4}$ \\ Program Studi Teknik Informatika, Fakultas IImu Komputer \\ Universitas Lancang Kuning Pekanbaru
}

\begin{abstract}
ABSTRAK
Perkembangan dunia informasi saat ini semakin cepat memasuki berbagai bidang area, yang sedang berusaha memanfaatkan kecanggihan teknologi informasi masa kini. Masalah keamanan dan kerahasiaan sebuah database merupakan salah satu aspek yang sangat penting dari suatu sistem informasi. Sebuah informasi hanya ditujukan pada pihak tertentu, hal tersebut berhubungan dengan bagaimana sebuah informasi tidak dapat di akses oleh orang yang tidak berhak. File database adalah kumpulan file-file yang memiliki keterkaitan antara suatu file dengan file lainnya sehingga membentuk kumpulan data untuk menginformasikan suatu perusahaan, instansi dalam batasan tertentu untuk membentuk data baru dan informasi. Algoritma ElGamal merupakan sebuah algoritma yang diperkuat logaritma diskritnya dengan berdasarkan konsep kunci public. Algoritma ini pada umumnya digunakan untuk Digital Signature, kemudian dirombak sehingga bisa digunakan untuk enkripsi dan deskripsi. Pada proses ekripsi database pesan tersebut sebelumnya harus dikonversikan dalam kode ASCII terlebih dahulu karena algoritma ElGamal menggunakan bilangan bulat dalam perhitungannya. Pesan yang telah dienkripsi tersebut akan dikirimkan kepada penerima pesan yang mempunyai ElGamal secara teknis terletak pada kesulitan perhitungan logaritma diskrit pada modul prima yang besar, sehingga upaya menyelesaikan sebuah masalah logaritma ini menjadi sulit dipecahkan. Dengan menggunakan metode Algoritma ElGamal, proses enkripsi file database yang akan dienkripsi adalah isi data pada table (chipertext), file database masih dapat dibuka dan dilihat akan tetapi isi data pada table tidak dapat dibaca, kemudian proses dekripsi untuk mengembalikan file database yang telah dienkripsi kembali menjadi file awal (plaintext).
\end{abstract}

Kata kunci : Kriptogafi, Database, Algoritma ElGamal, Enkripsi, Dekripsi.

\section{PENDAHULUAN}

Salah satu perkembangan yang penting adalah semakin dibutuhkannya penggunaan alat pengolah data yang berfungsi untuk 
menghasilkan sebuah informasi yang dibutuhkan. Dengan menggunakan alat pendukung pengolah data yaitu komputer. Dengan adanya komputer sebagai alat pengolah data, maka semua bidang dalam suatu perguruan tinggi ataupun instansi dapat di komputersasikan. Masalah keamanan dan kerahasiaan database merupakan salah satu aspek penting dari suatu sistem informasi. Sebuah informasi hanya ditujukan bagi pihakpihak tertentu, hal tersebut terkait dengan bagaimana informasi tidak dapat diakses oleh orang yang tidak berhak. Pengamanan file pada database dapat dilakukan dengan menggunakan beberapa Algoritma Asimetris tabg dapat mengunci file database diantaranya seperti Algoritma ElGamal. Dalam hal ini, masih banyak orang yang belum mengerti bagaimana cara mengakses ataupun mengamankan file database sehingga data yang terhadap di dalamnya tidak dapat dilihat oleh orang lain. Hal ini disebabkan oleh sulitnya prosedur pengamanan komputer jika menggunakan fasilitas yang disediakan oleh masingmasing sistem operasi. Untuk itu, dibutuhkan sebuah aplikasi yang dapat dengan mudah dan cepat mengunci serta mengamankan komputer pengguna dengan menggunakan kata kunci yang di inputkan ke dalamnya.

Algoritma ElGamal merupakan cara mencari sebuah bilangan pangkat (x), pada sebuah bilangan bulat $(\mathrm{g})$. Dimana bilangan tersebut merupakan bilangan bulat lainnya (y) jika di modifikasi dengan bilangan $p$ (bilangan prima). Kerumitannya terletak pada malasah diskrit karena variable modul dan $\mathrm{x}$ adalah bilangan yang dicari berupa bilangan pangkat. Untuk memberkukat latar belakang permasalahan, penulis memasukkan jurnal yang berkaitan dengan Algoritmanya yang berjudul "Implementasi Algoritma ElGamal Dan Kode Hill Untuk Keamanan Database" Dalam penelitian di jelaskan bahwa penerima pesan membuat kunci publik yang tetap dipegangnya dan kunci rahasia yang diserahkan pada pembuatan pesan. Kemudian, pesan yang akan dikirimkan oleh pembuat pesan mengenkripsi pesannya dengan kunci publik yang diterimanya.

Pesan itu sebelumnya harus dikonversikan dalam kode $A S C / /$ terlebih dahulu karena Algoritma ElGamal menggunakan bilangan bulat dalam perhitungannya. Pesan yang dienkripsi tersebut kemudian di kirimkan kepada penerima pesan yang mempunyai kunci rahasia untuk mendeskripsikan pesan yang telah dienkripsi.

\section{KAJIAN PUSTAKA}

Ada beberapa penelitian yang telah dilakukan pada algoritma ElGamal. Kajian terdahulu diambil dari penelitian Dafirius Lombu, Siska Dame Tarihoran, Irwan Gulo Universitas STMIK Budidarma Medan “Kombinasi Mode Cipher Block Chaining Dengan Algoritma Triangle Chain Cipher Pada Penyandian Login Website" (Lombu et al., 2018) bahwa Algoritma yang berjudul ElGamal harus bersanding berdasarkan kombinasi mode operasi Chipper Block Chaining (CBC) dan Algoritma Triangle Chain 
Chiper (TCC) dapat diterapkan untuk menyandingkan data login user website serta cukup memadai untuk menangkal penyerangan record database oleh pihak yang tidak berhak karena tingkat kesulitan dalam memecahkannya sangat rumit.

Penelitian dari Neti Rusri Yanti, Alimah, Desi Afrida Ritonga "Implementasi Algoritma Data Encryption Standard Pada Penyandian Record Database" Universitas STMIK Budidarma Medan (Komputer et al., 2018) penyandian record database berdasarkan Algoritma DES mampu mempersulit pihak-pihak lain untuk mengerti isi dari record database.

Penelitan Winda Sari, Yani Maulita, Achmad Fauzi "Analisa Algoritma Elgamal Dalam Penyandian Data Sebagai Keamanan Database" Universitas STMIK Kaputama (Komputer et al., 2018) Program aplikasi Kriptografi dapat menyediakan sebuah file yang bersifat rahasia sehingga file database terjamin keamanannya.

Penelitian M. Taufik Tamam, Wakhyu Dwiono, Tri Hartanto "Penerapan Algoritma Kriptografi ElGamal untuk Pengaman File Citra" (Tamam et al., 2010) File berekstensi bitmap dapat diubah ekstensinya menjadi "este" melalui proses enkripsi dan dapat di kembalikan ekstensinya ke bitmap melalui proses dekripsi.

Penelitian dari Deny Adhar "Pengamanan Sqlite Database Menggunakan Kriptografi Elgamal" mahasiswa Universitas STMIK Potensi Utama Medan (Adhar, 2014) Sistem Kriptografi Algoritma ElGamal terdiri atas dua proses yaitu proses Enkirpsi dan proses Dekripsi. Proses Enkripsi dibutuhkan kunci public dan kunci private, sedangkan proses Dekripsi membutuhkan bilangan prima dan kunci private sehingga dapat lebih optimal dalam pengamanan data.

Peneliatian dari Albi Dwi Haryono dan Pipin Farida Ariyani tentang "Aplikasi Pengaman Basis Data Pada Nuklindo Lab Dengan Algoritma Elgamal Dan Affine Cipher" Universitas Budi Luhur (Haryono et al., 2018) Enkripsi ElGamal dan Affine Cipher ini dapat diimplementasikan pada aplikasi pengamanan database dengan menggunakan bahasa pemograman Java dan database MySQL.

Penelitian dari Deny Adhar "Implementasi Algoritma DES (Data Encryption Standard) Pada Enkripsi Dan Deskripsi SMS Berbasis Android" Universitas Potensi Utama (Adhar, 2019) DES merupakan sebuah Algoritma penyandian yang simetris, dimana untuk proses enkripsi dan dekripsi pesan harus menggunakan kunci yang sama. Jadi seorang criptanalis memahami Algoritma yang digunakan untuk menyandikan pesan tersebut, tapi kalau tidak mengetahui kunci yang digunakan, makan tidak aman dapat mendekripsi pesan tersebut.

Penelitian dari Fajar Ibnu Wicaksana dan Ir. Siswanto, M.M "Kriptografi Database Menggunakan Algoritma El-Gamal Berbasis Web" Universitas Budi Luhur (Wicaksana \& Siswanto, 2018) Aplikasi Kriptografi dapat menggunakan Algoritma ElGamal sebagai sistem keamanan database. Jadi dengan adanya Aplikasi Kriptografi proses pengamanan 
databaselebih aman.

Penelitan Gama Anugrah Sahputra dan Titin Fatima tentang "Implementasi Kriptografi Dengan Metode Algoritma ElGamal Untuk Keamanan Database Berbasis Java Desktop Pada PT. Makmur Supra Nusantara" Universitas Budi Luhur (Sahputra et al., 2018) Proses penyimpanan data ke database lebih aman karena menggunakan Kriptografi ElGamal sebagai aplikasi Algoritma.

Penelitian Peter Jaya dan Safitri Juanita yang berjudul "Aplikasi Pengamanan Basis Data Dengan Algoritma RSA Dan Wake Berbasis Desktop" Universitas Budi Luhur (Jaya et al., 2018) berdasarkan proses perancangan, pembuatan, dan pengujian sebuah aplikasi enkripsi berbasis data, dapat di simpulkan bahwa metode Algoritma RSA dan WAKE yang digunakan dapat di implementasikan menggunakan bahasa pemograman Java.

Penelitian Gilang Ammary dan Sri Mulyati "Aplikasi Kriptografi Untuk Keamanan Databse Dengan Metode RC4 Dan Elgamal Berbasis Web Pada JXL DESIGN CO" Universitas Budi Luhur (Ammary et al., 1987) Enkripsi RC4 (Rivest Code 4) dan ElGamal dapat di implementasikan terhadap aplikasi keamanan database menggunakan bahasa pemograman Java Web dan database MySQL serta menggunakan record data yang masuk ke dalam database dengan teknik Kriptografi menggunakan RC4 dan ElGamal sehingga data yang tersimpan sulit terbaca.

Penelitian Sandi Yusmantoro, Edy Hermansyah, Rusdi Efendi "Rancang Bangun Aplikasi Pengamanan Keaslian Surat Izin Tempat Usaha Menggunakan Algoritma Elgamal Dan Secure Hash Algorithm 256" Universitas Bengkulu (Yusmantoro et al., 2014) menyatakan bahwa Algoritma EIGamal merupakan sebuah aplikasi pengamana keaslian SITU dan dapat digunakan untuk mengamankan SITU dan melakukan autentikasi.

Penelitian Fitri Angelina Siahaan "Implementasi Algoritma Unary Coding Untuk Mengkompresi Teks Terenkripsi ElGamal" Universitas STMIK Budi Darma (Siahaan et al., 2018) Penerapan Algoritma ElGamal dalam penyandian file text dapat dilakukan dengan kunci publik yang dibangkitkan terlebih dahulu kemudian membagi file text menjadi blokblok cipher untuk di enkripsi dan menggabungkan kembali blok tersebut menjadi ciphertext.

Penelitian Edi Rahmansyah "Implementasi Algoritma Elgamal Dengan Pembangkit Bilangan Prima Lehmann Dan Algoritma Least Significant Bit (LSB) Dengan Cover Image Bitmap Untuk Keamanan Data Text" Universitas STMIK Budi Darma (Rahmansyah, 2019) Penyandian dengan metode ElGamal dapat menanfaatkan operasi aritmatika biasa, ElGamal dapat diimplementasikan untuk menyandikan sebuah pesan agar tidak mudah untuk diketahui oleh pihak lain.

Penelitian dari Nonik Indahwati dan Agus Prihanto "Penerapan 
Algoritma Kriptografi Asimetris Elgamal dengan Modifikasi Pembangkit Kunci terhadap Enkripsidan Dekripsi Gambar Warna" Universitas Negeri Surabaya (Indahwati \& Prihanto, 2019) Dapat menghasilkan sebuah sistem yang dapat melakukan enkripsi dan dekripsi menggunakan Algoritma Asimetris ElGamal yang memiliki tampilan antarmuka.

Penelitian dari Eko Aribowo "Aplikasi Pengamanan Dokumen Office Dengan Algoritma Kriptografi Kunci Asimetris Elgamal" Universitas Ahmad Dahlan Yogyakarta (Kriptografi \& Asimetris, 2008) Implementasi program bisa menghasilkan sebuah aplikasi yang dapat mengubah isi suatu dokumen (plaintext) yang berupa teks, tabel dan gambar menjadi kodekode yang tidak dikenal (ciphertext) menjadi dokumen aslinya (plaintext).

Penelitian Ericko "Penerapan Hybrid Cryptosystem Menggunakan Algoritma Hill Cipher $3 \times 3$ dan Algoritma Elgamal pada Instant Messaging Berbasis Android" Universitan Sumatera Utara (Utara et al., 2018) Penerapan Algoritma Hill Cipher $3 \times 3$ dan Algoritma ElGamal bisa melakukan proses enkripsi kunci simetris, dekripsi kunci simetris, enkripsi teks dan dekripsi teks.

Penelitian dari Heru Aditya, Intan Nur Farida, Risky Aswi Ramadhani "Penerapan Algoritma Elgamal dan SSL Pada Aplikasi Group Chat" Universitas Nusantara PGRI Kediri (Aditya et al., 2018) Algoritma Kriptografri ElGamal mampu diterapkan dalam aplikasi grup chat pada proses penginputan pesan ke database dan menampilkan pesan dari database ke interface aplikasi.

Penelitan dari Diah Retno Palupi dan Umi Rosyidah "Implementasi Algoritma Hill Cipher Dalam Penyandian Data Nilai Akhir Semester Pada Program Studi TI-S1 Tahun Ajaran 2014/2015 Denganmenggunakan Kode ASCII" Universitan Dian Nuswantoro (Cipher et al., 2015) Bahwa pengujian Algoritma Hill Cipher dalam penyandian sebuah data pada nilai akhir semester dapat dilakukan, dan metode Algoritma Hill Cipher dengan menggunakan kode ASCII telah diimplementasikan kedalam penginputan nilai siswa.

Penelitian dari Faqihudin Al-Anshori dan Eko Ariwibowo tentang "Implementasi Algoritma Kriptografi Kunci Publik Elgamal Untuk Proses Enkripsi Dan Dekripsi Guna Pengamanan File Data" Universitas Ahmad Dahlan Yogyakarta (Ahmad \& Yogyakarta, 2014) pengujian aplikasi menggunakan metode black box test dan alpha test kepada responden, memunculkan hasil proses enkripsi dan dekripsi sesuai dengan kaidah Algoritma Kriptografi EIGamal. 


\section{METODE PENELITIAN}

Pengumpulan data dilakukan untuk memperoleh data yang dibutuhkan dalam sebuah program aplikasi. Dalam penelitian ini teknik pengumpulan data yang dilakukan adalah:

Metode kepustakaan dan Browsing/Penelusuran Internet. Metode kepustakaan dimaksudkan untuk mendapatkan data-data yang diperlukan dalam hal menelaah dan menganalisis kenyataan yang ada pada obyek penelitian, yaitu dengan cara mengumpulkan, mempelajari dan memahami buku-buku referensi serta laporan tugas akhir yang berhubungan dengan penelitian ini.Metode wawancara Merupakan metode yang dilakukan dengan mengajukan pertanyaan atau tanya jawab secara langsung dengan steakholder yang terlibat di dalam system. Observasi Yaitu pengumpulan data melalui pengamatan secara langsung terhadap cara kerja para pengguna fitur pengamaanan file data yaitu algoritma sistem kriptografi kunci umum metode algoritma ElGamal, dilakukan dengan maksud untuk mengetahui tentang cara, prosedur atau sistem kriptografi kunci umum dan pengumpulan data secara langsung, sehingga dapat mengetahui segala permasalahan yang berkaitan dengan sistem kriptografi kunci umum dengan algoritma ElGamal. Running dan Mengamati Program Kriptografi Untuk mendapatkan kekurangan dan kelebihan suatu program kriptografi yang sudah dibangun maka salah satu caranya adalah dengan memberikan quisioner atau angket untuk mengetahui sejauh mana aplikasi ini nantinya akan sangat berguna atau tidak. (MASIH KURANG)

\section{HASIL DAN PEMBAHASAN}

\subsection{Analisa Kebutuhan Sistem}

Dari penelitian ini dihasilkan sebuah program aplikasi enkripsi dan dekripsi elgamal yang dibangun menggunakan visual basic. Aplikasi ini dapat digunakan oleh user baik secara umum maupun untuk suatu organisasi atau perusahaan. Aplikasi ini dirancang untuk mengenkripsi perpindahan file data yaang akan dimankan. User diberi kebebasan untuk mengamankan data file itu, bisa berupa dta file bebentuk rtf, txt, dn pesan singkat. Hasil dari penelitian akan menghasilkan sebuah program aplikasi yang:

a. Dapat mengubah file asli menjadi file yang terenkrikpsi di mana isi file tidak dapat dibaca.

b. Dapat mengembalikan file yang tidak bisa dibaca menjadi file 
aslinya dengan metode elgamal tanpa merusak dan merubah isi file tersebut.

c. Dapat mengubah pesan asli berupa plaintext menjadi chipertext yaitu berupa kode-kode yang tidak bisa terbaca.

\subsection{Perancangan}

a. Flowchart

Dalam penelitian ini flowchart dibuat untuk mengetahui dan merancang arah aliran program yang akan dibuat, agar sistem yang dibuat dapat berjalan sebagai mana mestinya dan menghasilkan output berupa hasil dari pengiriman baik itu berupa pesan maupun file yang diinputkan. Dalam penelitian ini proses enkripsi dan dekripsi perpindhan file data baik itu rtf, txt, dan pesan singkat menggunakan salah satu metode kriptografi, yaitu Elgamal. Pada Gambar 1 (a) dan 1 (b) menunjukan proses enkripsi file dan proses dekripsi file. Adapun flowchart proses enkripsi file dan proses dekripsi file adalah sebagai berikut :

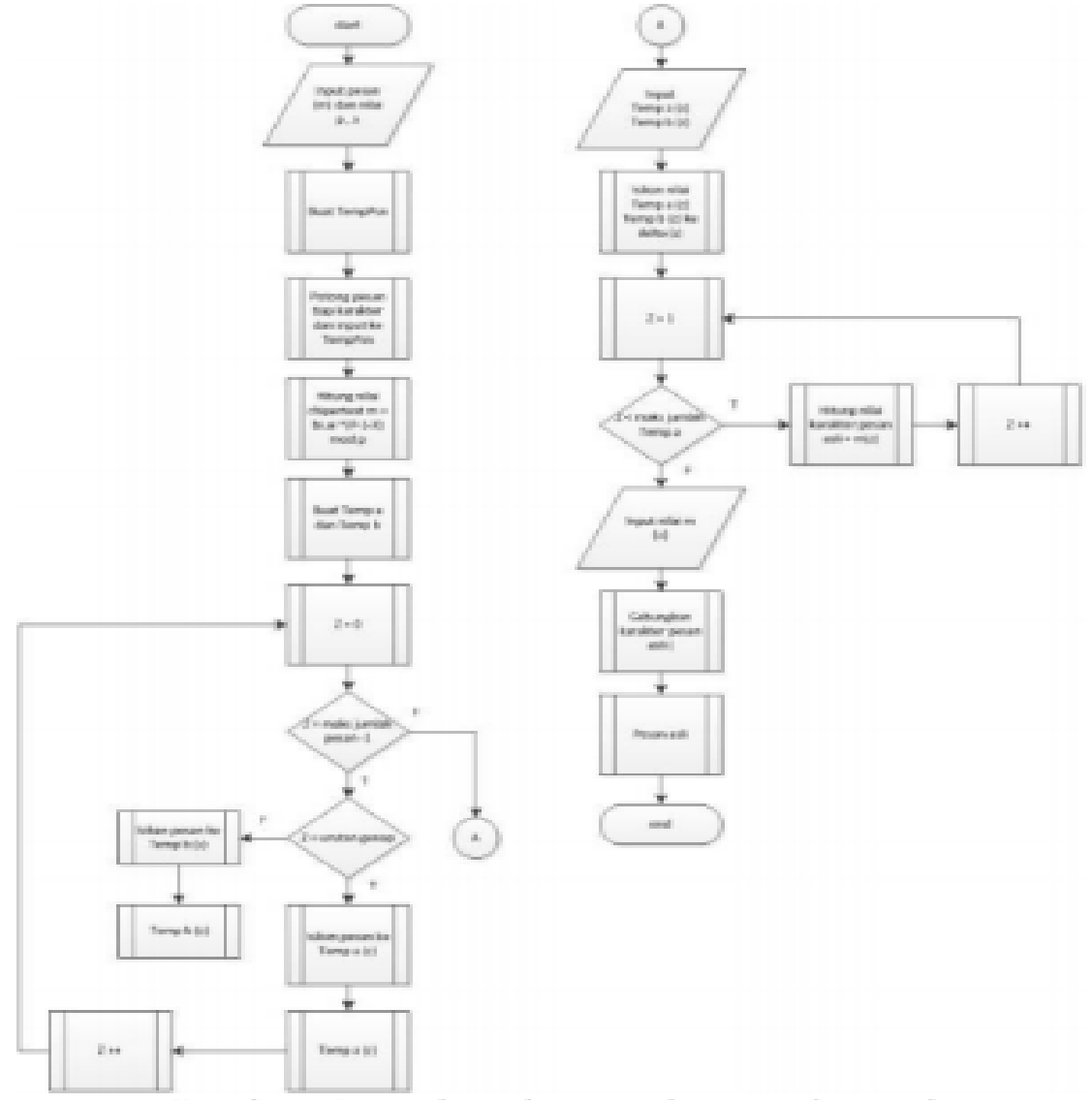

(BUAT GAMBAR FLOWCHART NYA) 
b. Perancangan Struktur Menu

Sebelum merancang form dan program yang akan dibuat terlebih dahulu dibuat rancangan struktur menu programnya. Tahap ini dilakukan agar diperoleh sistem yang efektif dan efisien sehingga pengguna lebih mudah memakainya.

c. Perancangan Input-Output

Tahap perancangan input-output merupakan tahapan perancangan interface, agar program aplikasi dapat berinteraksi dengan baik dengan user. Sehingga output yang dikeluarkan sesuai dengan harapan yang diinginkan oleh user. Setelah pembuatan struktur menu diatas akan dirancang tiga form, yaitu form utama, form enkripsi, form dekripsi.

\section{IMPLEMENTASI PROGRAM}

\subsection{Form Dan Coding}

Bahasa pemrograman Visual Basic akan sangat mendukung proses perancangan form yang telah ditentukan sebelumnya. Dalam penelitian ini kita akan menggunakan Visual Basic sebagai compilernya. Dalam pembuatan aplikasi ini diperlukan 3 form seperti yang sudah direncanakan pada rancangan yang ada di atas antara lain adalah form menu utama, form enkripsi dan form dekripsi.

\subsection{Menu Utama}

Pada menu utama ini memiliki fungsi untuk menampilkan tampilan awal program yang memudahkan penggunanya. Seperti proses enkripsi dan deskripsi yang ada pada pada menu utama, berikut adalah Gambar 2 yang menampilkan tampilan menu utama dari program ini. 


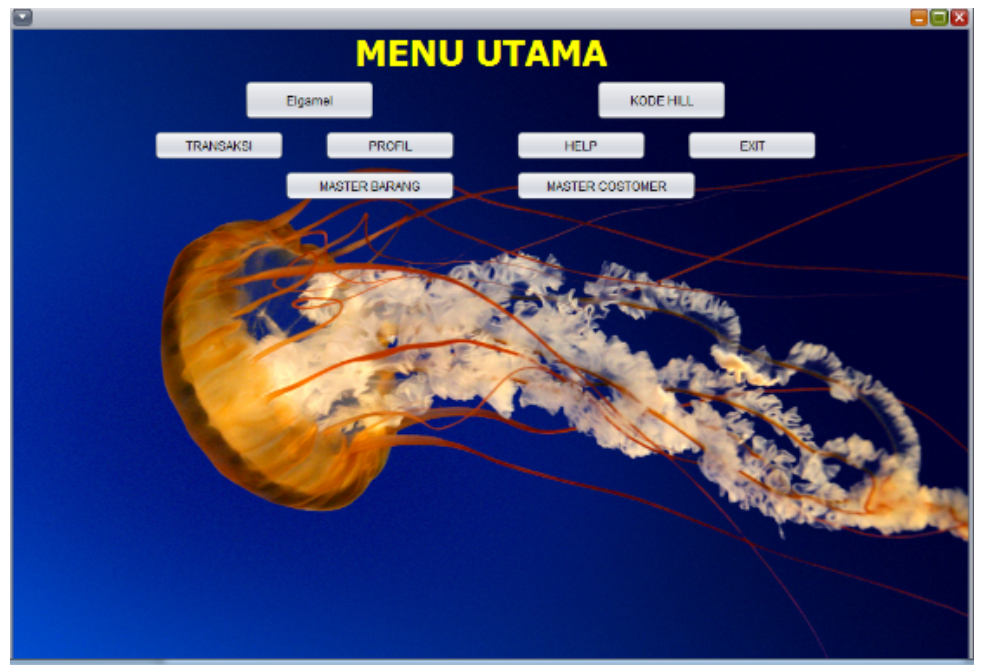

(GAMBAR MENU UTAMA)

5.3. Tampilan Layar FormTransaksi

Tampilan layar form Transaksi pada gambar di ba wah ini terlihat pada saat usermengklik tombol Transaksi pada form menu utama.

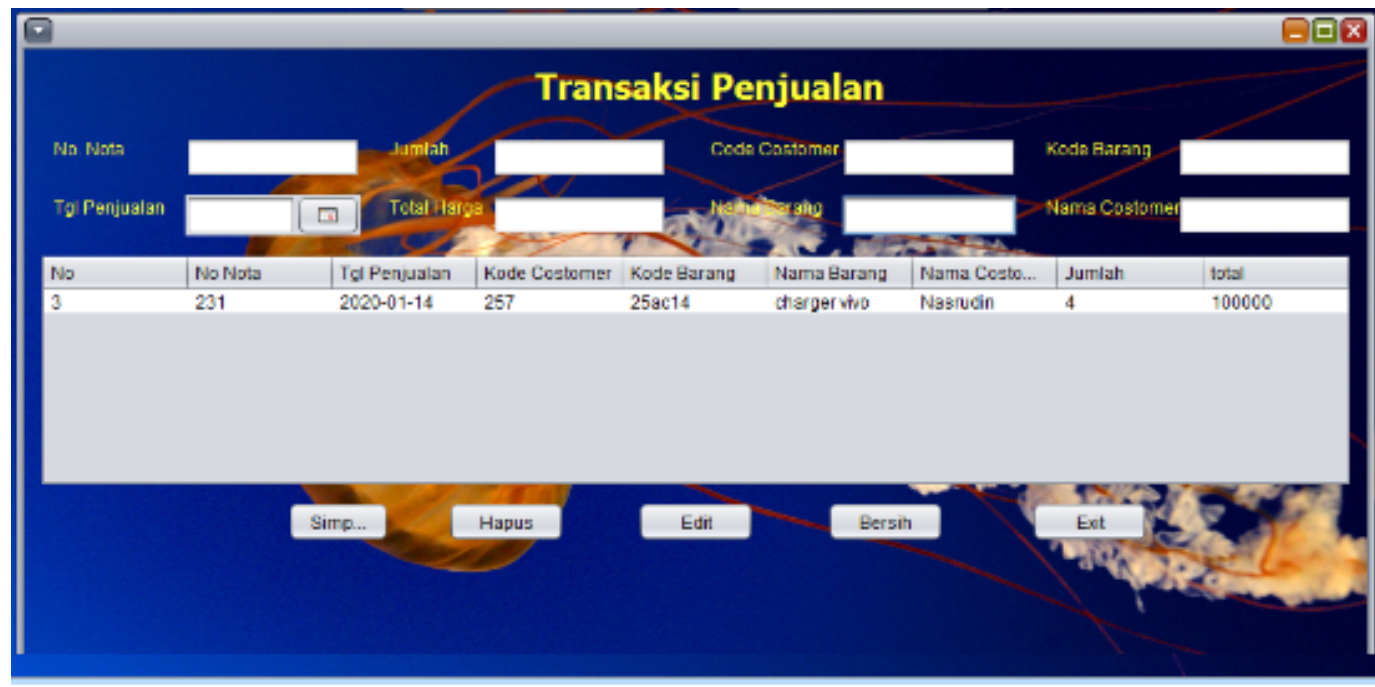

(GAMBAR FORM TRANSAKSI)

\subsection{Enkripsi Perpindahan Data File}

Selanjutnya pada form enkripsi perpindahan data file digunakan untuk membuka komponen yang ada pada form enkripsi seperti mengenkripsi pesan/file yang sudah di sediakan ada form enkripsi file. Berikut adalah Gambar tampilan form enkripsi. 


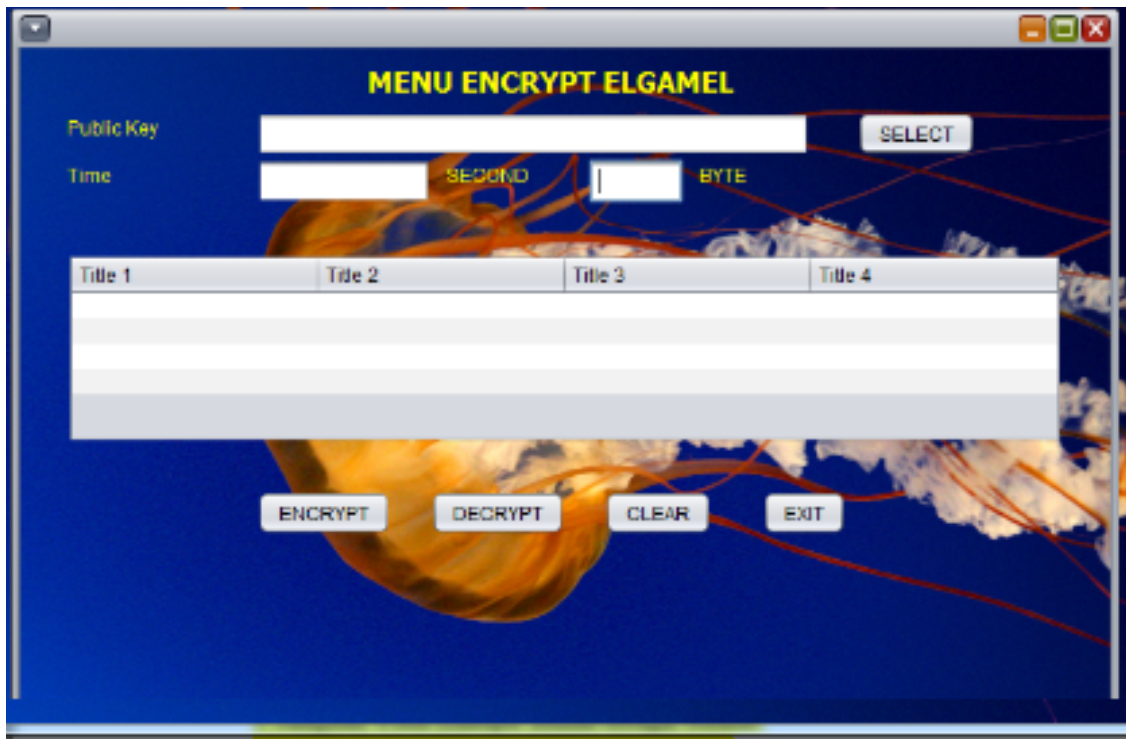

(GAMBAR FORM ENKRIPSI)

5.5 Dekripsi Perpindahan Data File

Sama seperti halnya proses enkripsi pada proses deskripsi akan melalui beberapa fungsi yang ada pada aksi tombol deskripsi yaitu dengan membuka file yang sudah terenkripsi sekaligus mengembalikan file asli yang telah di enkripsi tadi. Adapun tampilan form dekripsi dapat diliihat seperti Gambar. seperti yang ada di bawah ini.

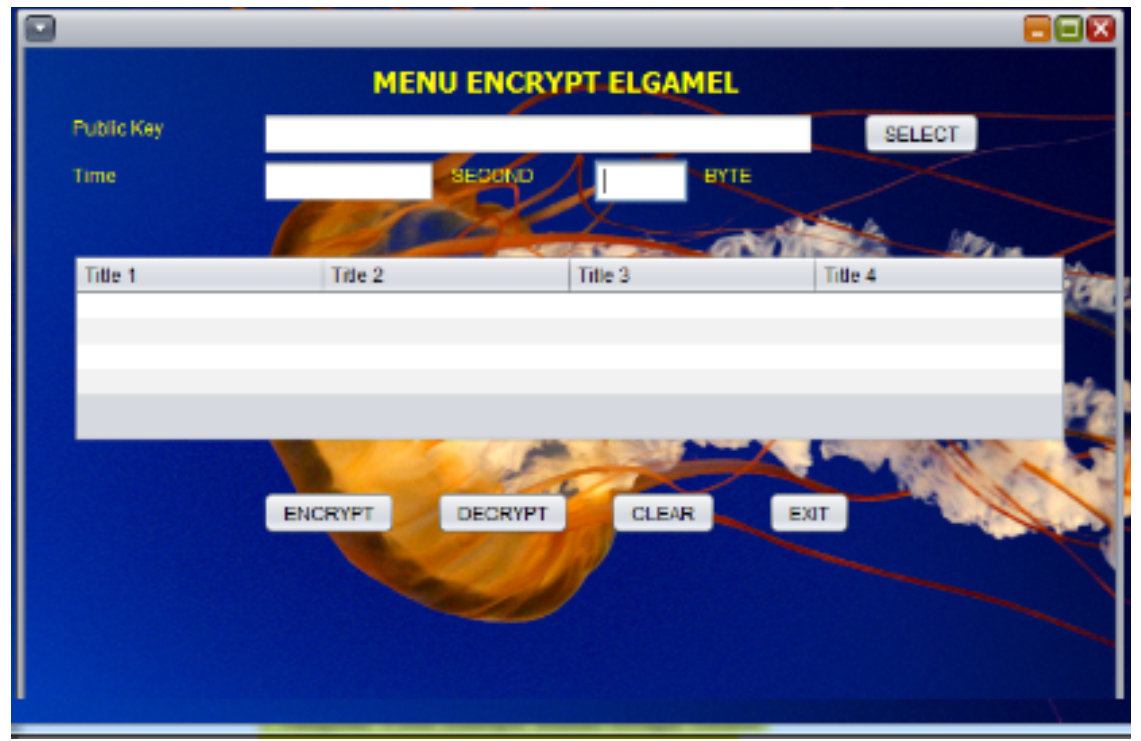

(GAMBAR FORM DEKRIPSI)

\section{HASIL PROGRAM}




\subsection{Form Enkripsi}

Langkah yang dilakukan setelah muncul menu utama seperti ini adalah memilih enkripsi untuk menjalankan program ini dengan klik tombol enkripsi maka otomatis akan langsung masuk ke sistem berikutnya. Pada Gambar 5 Tampilan Form Enkripsi adalah sebagai berikut:

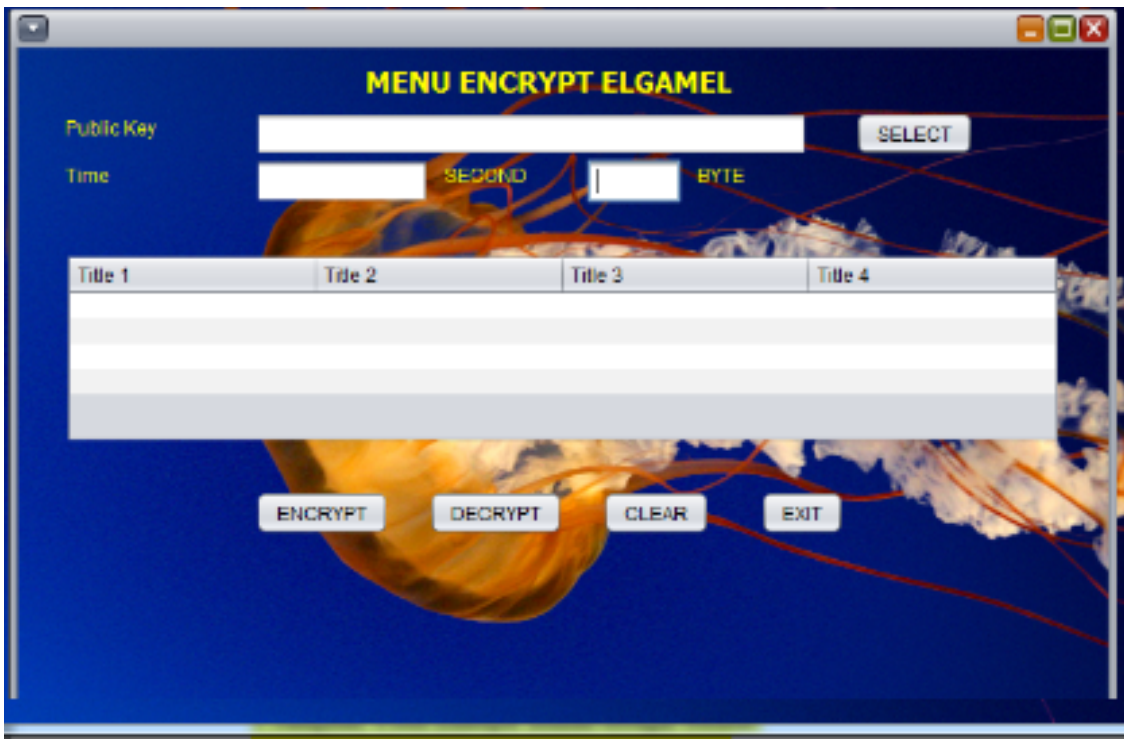

(GAMBAR TAMPILAM FORM ENKRIPSI)

\subsection{FORM DEKRIPSI}

Selanjutnya adalah ketika selesai mengenkripsi hasil dari enkripsi tadi maka akan langsung beralih ke form Dekripsi. Setelah itu akan menghasilkan Form Dekripsi seperti yang diinginkan, seperti pada Gambar 6 Tampilan Form Dekripsi sebagai berikut : 


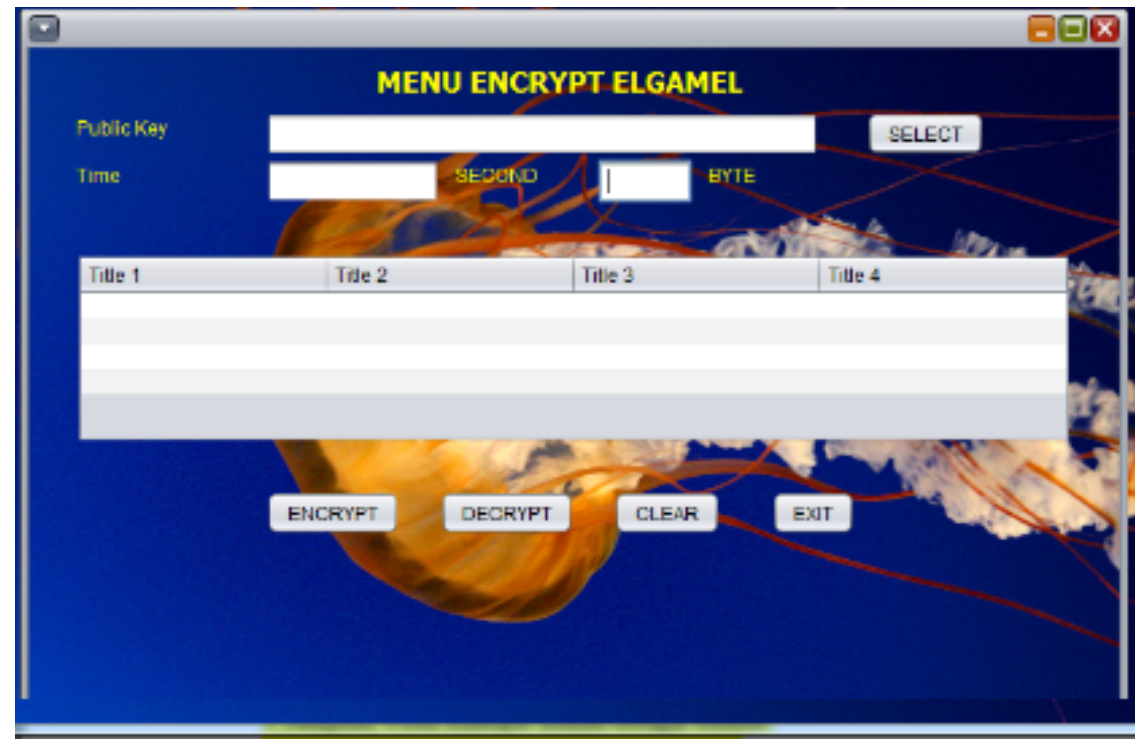

(GAMBAR TAMPILAN FORM DEKRIPSI)

\section{KESIMPULAN}

Berdasarkan hasil penelitian dan pembahasan dapat disimpulkan beberapa hal sebagai berikut : 


\section{DAFTAR PUSTAKA}

Adhar, D. (2014). PENGAMANAN SQLITE DATABASE MENGGUNAKAN KRIPTOGRAFI ELGAMAL. 432-437.

Adhar, D. (2019). IMPLEMENTASI ALGORITMA DES (DATA ENCRYPTION STANDARD) PADA ENKRIPSI DAN DESKRIPSI SMS BERBASIS ANDROID. 3(2), 53-60.

Aditya, H., Farida, I. N., \& Ramadhani, R. A. (2018). Penerapan Algoritma Elgamal dan SSL Pada Aplikasi Group Chat. 2(1), 48-56.

Ahmad, U., \& Yogyakarta, D. (2014). JURNAL INFORMATIKA Februari 2014.

Ammary, G., Mulyati, S., Studi, P., Informatika, T., Informasi, F. T., Luhur, U. B., Utara, P., \& Lama, K. (1987). APLIKASI KRIPTOGRAFI UNTUK KEAMANAN DATABSE DENGAN METODE RC4 DAN ELGAMAL BERBASIS WEB Aplikasi Kriptografi Untuk Keamanan Databse Dengan Metode Rc4 Dan Aplikasi Kriptografi Untuk Keamanan Databse Dengan Metode Rc4 Dan. 7(2), 815-820.

Cipher, H., Data, E., Data, D., \& Data, B. (2015). IMPLEMENTASI ALGORITMA HILL CIPHER DALAM PENYANDIAN DATA NILAI AKHIR SEMESTER PADA PROGRAM STUDI TI-S1 TAHUN AJARAN 2014 / 2015 DENGAN. 1-10.

Haryono, A. D., Ariyani, P. F., Informasi, F. T., Luhur, U. B., Utara, P., Lama, K., \& Cipher, A. (2018). APLIKASI PENGAMAN BASIS DATA PADA NUKLINDO LAB. 1(1), 186-192.

Indahwati, N., \& Prihanto, A. (2019). Penerapan Algoritma Kriptografi Asimetris Elgamal dengan Modifikasi Pembangkit Kunci terhadap Enkripsi dan Dekripsi Gambar Warna. 01, 97-103.

Jaya, P., Juanita, S., Informasi, F. T., Luhur, U. B., Utara, P., Lama, K., \& Pelanggan, D. (2018). APLIKASI PENGAMANAN BASIS DATA DENGAN ALGORITMA. 7(1), 352-358.

Komputer, J. S., Yanti, N. R., \& Ritonga, D. A. (2018). Implementasi Algoritma Data Encryption Standard Pada Penyandian Record Database. 1, 23-32.

Kriptografi, A., \& Asimetris, K. (2008). JURNAL INFORMATIKA Vol 2, No. 2, Juli 2008. 2(2), 209-219.

Lombu, D., Tarihoran, S. D., \& Gulo, I. (2018). Kombinasi Mode Cipher Block Chaining Dengan Algoritma Triangle Chain Cipher Pada Penyandian Login Website. 1, 1-11.

Rahmansyah, E. (2019). Implementasi Algoritma Elgamal Dengan Pembangkit Bilangan Prima Lehmann Dan Algoritma Least Significant Bit (LSB) Dengan Cover Image Bitmap Untuk Keamanan Data Text. 6(1), 79-84.

Sahputra, G. A., Fatimah, T., Studi, P., Informatika, T., Informasi, F. T., Luhur, U. B., Utara, P., \& Lama, K. (2018). ELGAMAL UNTUK KEAMANAN DATABASE BERBASIS JAVA. 7(1), 309-315.

Siahaan, F. A., Studi, P., \& Informatika, T. (2018). MENGKOMPRESI TEKS TERENKRIPSI EL GAMAL. 2(1), 26-34.

Tamam, M. T., Dwiono, W., \& Hartanto, T. (2010). Penerapan Algoritma Kriptografi ElGamal untuk Pengaman File Citra. $M(1), 8-11$.

Utara, U. S., Utara, U. S., \& Utara, U. S. (2018). Penerapan Hybrid Cryptosystem Menggunakan Algoritma Hill Cipher 3 × 3 dan Algoritma Elgamal pada Instant Messaging Berbasis Android.

Wicaksana, F. I., \& Siswanto, I. (2018). KRIPTOGRAFI DATABASE MENGGUNAKAN ALGORITMA EL-GAMAL BERBASIS WEB. 1(1), 224-228.

Yusmantoro, S., Hermansyah, E., \& Efendi, R. (2014). PENGAMANAN KEASLIAN SURAT ELGAMAL DAN SECURE HASH ALGORITHM 256 STUDI KASUS : BADAN PELAYANAN PERIZINAN TERPADU (BPPT) KOTA BENGKULU. 2(1), 28-36. 